\title{
Toward a Competent Structuralist Archaeology: A Contribution from Historical Studies
}

\author{
David B. Small \\ Department of Classical Studies, 2016 Angell Hall, University of Michigan, \\ Ann Arbor, Michigan 48109-1003 \\ Received February 20, 1986
}

\begin{abstract}
This paper examines the present position of structuralist archaeology in respect to the use of ethnoarchaeology. It concentrates on the present inability of a structuralist approach to resolve two contentious issues: the utility of ethnoarchaeological analogy in specific cases and the methodology of establishing more general present-past linkage. In respect to the first issue, the argument is that the additional information supplied by historical documentation permits the construction of general paradigms of ideational behavior and enables a more positive use of specific analogy. As to the second, historical archaeology can be used to isolate general ideational principles and generalizations about their correlations, which offers a methodological counterpart to current approaches to establishing broad present-past linkage in functionalist archaeology. (1) 1987 Academic Press, Inc.
\end{abstract}

\section{INTRODUCTION}

Over 10 years ago Edmund Leach (1973:762) predicted that structural interests would soon become fashionable in archaeology. Today, the rising interest in structuralist approaches to archaeology shows that his view of the future was correct (e.g., Hodder, 1982a; Fritz 1978). Setting itself in opposition to "functionalist" archaeology, which has concentrated on topics such as discard behavior, site size, energy expenditure in tool making, etc., structuralist archaeology tries to understand the ideational background to archaeological material patterns.

Recent work has done much to establish a methodology for a structuralist archaeology (Hodder 1982a, 1982b; Wylie 1982). Although its goals may be different, structuralist archaeology is broadly similar in its methodology to established functionalist approaches. Both use enthoarchaeological observations, analogies to modern observed cultures, whether they be English urban or Austrialian aborigine, to achieve cultural models in past contexts. Because of its methodological similarity, structuralist archaeology must address two issues of debate in the general use of ethnoarchaeology: (1) the utility of using analogy in specific archaeo- 
logical cases to build models of past behavior and to test hypotheses gained from these models, and (2) the methodology of establishing generalizations, "laws," about the correlation of behavior to material culture, which could be used to establish broad cross-cultural linkages between ethnoarchaeological observations and past cultures.

Both these concerns are closely intertwined of course, and as Watson (Gould and Watson 1982:357) notes, the goal of one often incorporates the use of the other.

The concerns with the use of analogy in the first issue have been recently addressed by Gould (1980; Gould and Watson 1982). He observes that there is a very good chance that there is no ethnographic or ethnohistorical counterpart for the archaeological example. What we see today is an imperfect picture of the past; primitive cultures are heavily acculturated and many unique cultures are lost. These problems are further aggravated by an inability to understand the behavior behind the material pattern, which often results in attempts to strengthen analogy by increased number of similarities, which however might share little behavioral correlation. In this same vein Gould warns that resemblances cannot account for variability, i.e., contextual variability, which might have direct impact on the archaeological record, is unseen in formal similarities.

In reference to the second issue, that of establishing general principles of linkage, Watson (Gould and Watson 1982:358) recently summed up the declared goals of most archaeologists in linking present to past. The aim is to gain an understanding of a "principle of generic uniformity for present and past cultural systems." These goals have been the concern of several functionalist theorists. For example, Binford (1978), has concentrated on a biological concept of adaptation as a potential source for cross-cultural linkage. Schiffer (1976) as well has proposed cross-cultural "laws" whose links to other cultures should be based on uniform principles of deposition.

Differing in definition on the term analogy, but perhaps really applying the same methodology, Gould has presented the latest contribution to this study (Gould 1980; Gould and Watson 1982). His own attempt centers around energy expenditure. Certain materials would only allow a narrow range of behavior in any cultural context. His example is tool making.

Obviously, the direction of these functionalist approaches, such as those of Gould and Binford, are inapplicable in structuralist endeavors. Unfortunately, while significant effort has been spent on structuralist theory, little has been applied to its direct application, where structuralist archaeology would be forced to address our two areas of concern. Methodological development remains structuralist archaeology's greatest challenge. 
The purpose of this paper is to show how structuralist archaeology can address both these issues in the application of ethnoarchaeology through historic period research. The argument revolves around two theses: (1) Structuralist problems associated with the general use of analogy in specific cases can be overcome in historical archaeology. (2) Historical archaeology offers a methodology by which structuralists may isolate general ideational principles, which, like theories of deposition or biological adaptation, can serve as linkages to archaeological contexts.

\section{STRUCTURALIST CONCERNS OVER THE USE OF ANALOGY IN SPECIFIC CASES AND A REMEDY IN HISTORICAL ARCHAEOLOGY}

In his recent work, The Present Past, Hodder focused on the concerns of structuralist archaeologists in the use of ethnoarchaeological analogy (1982b:11-27). Like Gould he discredits formal analogy. His own answer to the problem is the use of relational rather than formal analogy in archaeological reasoning. Relational, in the definition used by Hodder, is an analogy based upon the processual and structural interrelations of material culture, rather than upon formal similarities. Obviously this type of analogy would have more epistemological force in structuralist research than mere formal similarity. Unfortunately, however, Hodder does not explain how we may develop relational analogies with the archaeological record (McIntosh 1985) when he argues that relational material from the past is unobtainable. Indeed, when it comes to the use of analogy in testing a hypothesis from a model on independent data, Hodder concludes:

"The archaeologist can never test the validity of the predictions themselves because there are no data available from the past concerning the relationship between the material culture and human activity." (1982a:23)

To this point, progress in developing a better use of analogy in structuralist research seems stymied. A logical remedy, relational analogy, is inapplicable. But it is arguable that this problem applies only to prehistoric investigation. In historic archaeology the archaeologist is often able to understand at least in a general way the ideational background and its correlations to his or her material patterns, making relational analogies possible. The following example demonstrates how it is possible to construct at least general models from texts for the structure behind archaeological material and how these general text-based models allow the historic archaeologist to search for relational analogic examples to refine and develop his final model. Furthermore, texts often supply enough detail for the archaeologist to impute the structure behind independent data, which offers hope of testing the hypotheses of his reconstructions. 


\section{The Particular Archaeological Case}

To support this argument the structure of community relations and the correlated spatial syntax for a small late Hellenistic community on Masada will be examined. Excavated in the late 1950s and early 1960s (AviYonah et al. 1956; Yadin 1965, 1966), this site, a large mesa on the southwest tip of the Dead Sea, was first fortified and elaborated by the Hasmonean kings (late second-early first century B.C.). Herod the Great (36-4 B.C.) later added a monumental northern stepped compound to the site during his reign. Masada also served as the seat of the defiant stand of the Sicarii zcalots against the Roman lcgions in A.D. 70.

\section{The Spatial Syntax}

There are several architectural building phases to the fortress. One phase isolates a small group of domestic buildings from the Hasmonean period., ${ }^{1, *}$ These buildings are IX, X, XI, XII, and XIII (Fig. 1). Building $X$, the western palace, (Fig. 2), is the most complex of all the buildings, offering several phases of construction. This discussion will therefore incorporate the other building first. They are less complex and afford a quicker understanding of the spatial syntax.

Physical separation isolates several spatial units for the community. The first is the space outside Masada's walls, which was sharply separated from space on the plateau by the mountain itself and the continuous casemate wall. The second unit was that space which fell between the inner face of the casemate wall and the imposing exterior surfaces of the houses.

The other units are within the houses. Although there is minor variation, their syntax is regular. Instead of single units of space, like the previous areas, those within the houses are spatial clusters, i.e., groups of rooms, separated from other room groups in the house. House XI (Fig. 3) is standard. An entrance unit(s) in the house was marked off from both the inner units and the plateau by a door at both ends of the vestibule. Past the entrance unit, physical separation within the houses isolated two additional spatial units, the courtyard unit and an " $L$ " shaped unit. The courtyard unit consists of the courtyard and radiating rooms. The " $L$ " shaped unit is separated from the courtyard unit by the east wall of the court. It starts in the southwest corner of the house and extends to the northeast, along the south and east. Its composition is that of a southwest corner room, a two columned room open to the court, a southeast corner room, and a number of rooms in the east wing, which includes a small

* See Notes section at end of paper for all footnotes. 


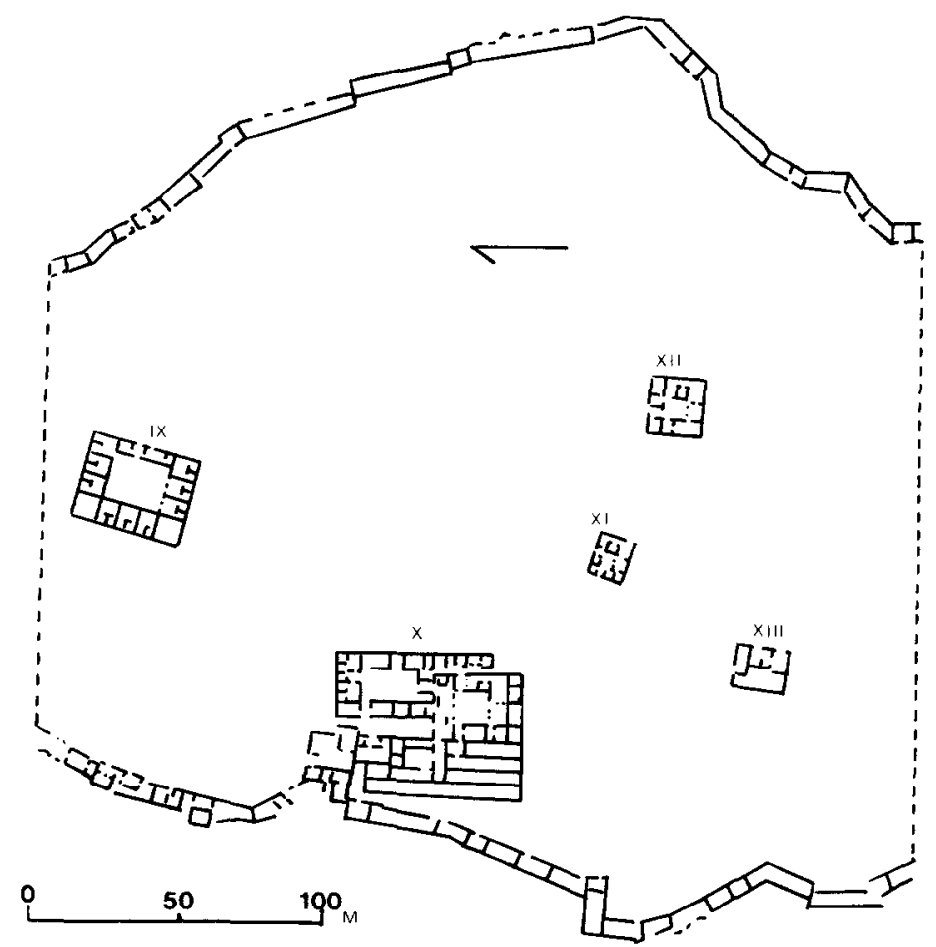

FIG. 1. Central region of Masada, showing houses of community, from Yadin (1965), by permission of the Israel Exploration Society.

room off a corridor. The " $L$ " shaped unit in house XI also has a private entrance/exit off the north entrance unit. Unlike the sharp separation of the other units, the courtyard unit and the " $L$ " shaped unit interface in a shared space, the two-columned room on the south side of the house.

Figure 4 is a model of our spatial syntax. This spatial model exhibits stability in architectural designing not only in its synchronic distribution throughout the community, but in its utilization in later community architectural expansion. It appears to have been little affected by wealth or other possible cultural attributes associated with an elite differentiation in the community. The southeastern block of the western palace (Fig. 2), contemporaneous with the houses, was more elaborate than its neighbors, but followed their spatial syntax. This block has a more appointed southeast room (Fig. 2A), which now had an anteroom; a more elaborate east wing, with a hidden court with a private exterior entrance/ exit replacing the smaller room north of the hallway in the other houses (Fig. 2B); an additional unit above the northern wing of the southeastern block; and a bath suite (Fig. 2C) in the courtyard unit. As the palace later expanded, it repeated the spatial syntax of the houses. For example, the 


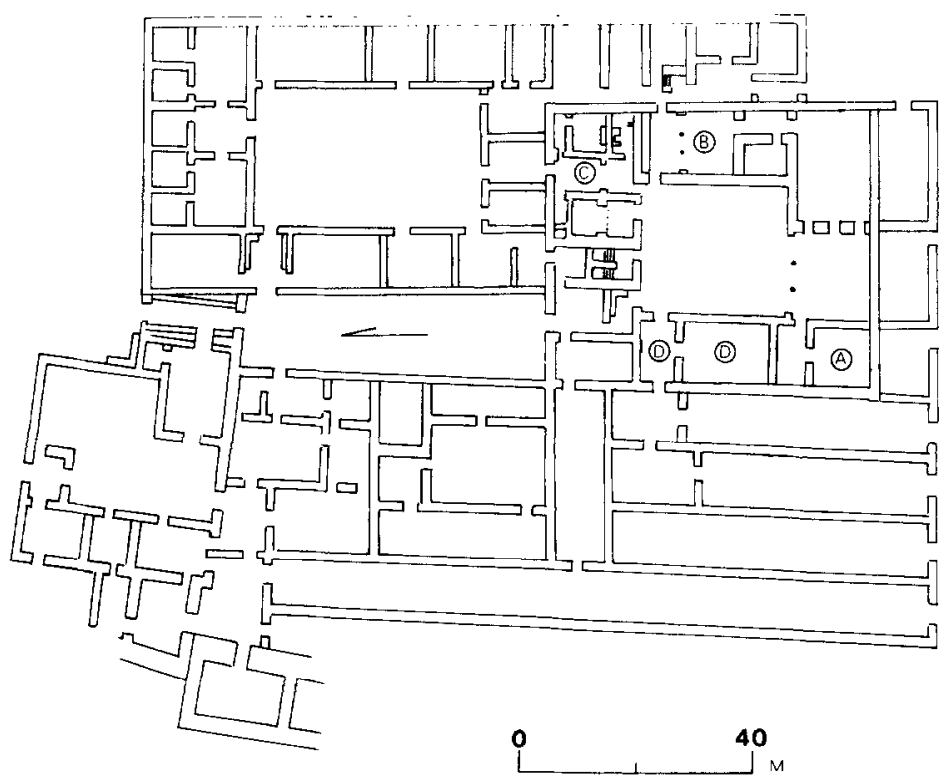

FIG. 2. Western palace on Masada, last phase of development.

original entrance of the southeast block was probably located in the west wing of the southeast block in the two-room open vestibule and side chamber combination (Fig. 2D). This same syntax was repeated in the northern entrance and can also be seen in the northeast block.

\section{Toward Structure and Subsystems Producing the Spatial Syntax}

A general paradigm. Analogy is used to identify the structure behind the spatial manipulation on Masada. The first aim is to obtain a general idea of the relationship between the architectural pattern on Masada and ideational behavior. The goal here is not a model of unilineal causality, but rather a system paradigm of interrelated variables that have bearing upon the spatial order of Masada (Tuggle et al. 1972).

The first step in this investigation is the gathering of ideational material from written records. This material is compartmentalized into two categories: structure and subsystems. Structure in this example comes close to Hodder's definition of "codes and rules according to which observed systems of interrelations are produced" (1982a:7). Subsystems, i.e., systems within this larger system paradigm, are those systems which are textually identified as correlated with the structure, the spatial symboling systems on Masada, and other subsystems as will be identified below. The concern for systems other than the symboling is necessitated by the 


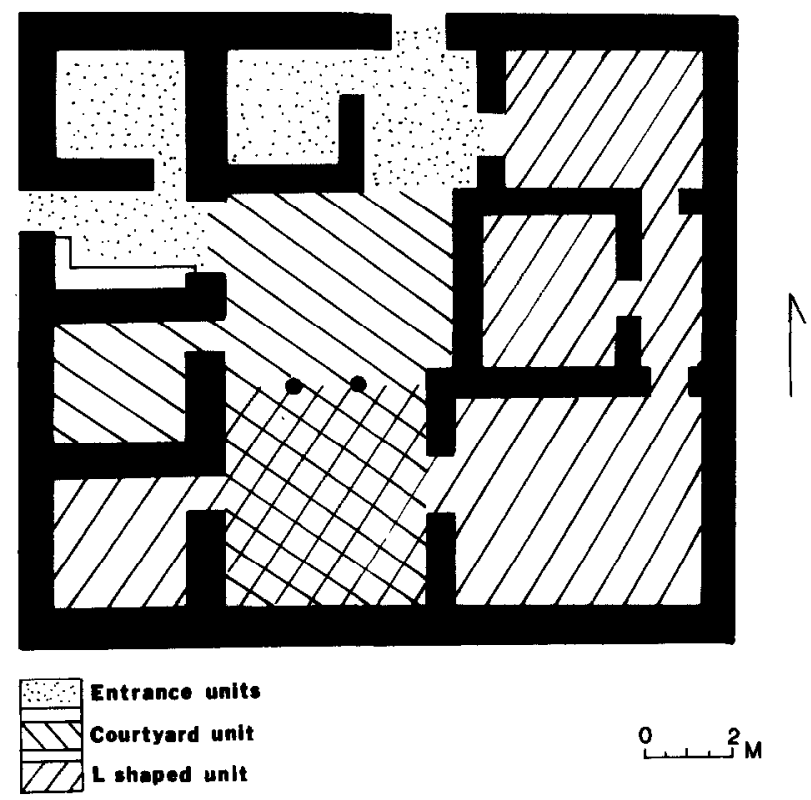

FIG. 3. House XI with spatial units indicated.

need to build a paradigm with as many significant correlated ideational systems as possible. This enables a narrowing of analogic arguments to examples with the most similar contexts.

The textual sources here are Josephos, the late first century A.D. Jewish historian; Philo, the early first century A.D. Jewish author; and the Mishnah, an early second century A.D. body of Jewish decrees, regulations, local customs, historical custom, and particular legal decisions from earlier periods.

Structure. In searching for gencral ideas of structure behind the architectural pattern on Masada, it is best to focus first on the broadest level possible. Analysis of the sources argues that the base line in community

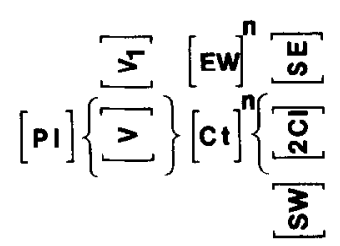

FIG. 4. Model of the spatial syntax for the Masada community $(\mathrm{E}=$ exterior, $\mathrm{Pl}=$ plateau, $\mathrm{V}=$ vestibule, $\mathrm{Ct}=$ courtyard, $\mathrm{SW}=$ southwest room, $\mathrm{SE}=$ southeast room, $\mathrm{EW}=$ east wing, $2 \mathrm{Cl}=$ two columned room, $\mathrm{n}=$ appended rooms). 
relations in Israel in this period was the interaction of men and women. Specific references in the Mishnah, Josephos, and Philo refer to rules or cases where contact between the sexes was strictly controlled. For example, prohibitions against women drinking alone with men are mentioned by Josephos (Wars 1:279). Philo condemns the exposure of Jewish women to foreign men (Flaccus 86-90) and the Mishnah prohibits a man (not the husband or close relative) from being alone with a woman (Kethuboth 4:12, 14). Further examples will be seen below, but it is apparent that general structure would center around rules limiting and controlling male-female relations within communities.

Other Subsystems. In addition to the unknown spatial symbolic subsystem behind the spatial syntax, two other special interaction subsystems are arguably correlated with both this general idea of structure and the spatial pattern. They are a religious and a family power maintenance subsystem. The religious subsystem classified women as periodically unclean and therefore separated them from others. Many sources refer to this focus on purity, which plays an important role in intrafamilial and family-community relations. The woman was inherently unclean. Her impurity was periodic, during mensturation and close after giving birth (Mishnah, Niddah 4:5-7). For the family, sexual relations during mensturation and close after birth made the husband unclean as well (Mishnah Kelim 1:4). This concern for purity additionally carried over into family-community relations (see Josephos, Wars 5:227, women barred from temple mount during menstruation).

The family power maintenance subsystem stressed purity of lineage and therefore the seclusion of women. This was especially noticeable in the upper classes, seen in the endogamous leanings of priestly marriage, and should be particularly pertinent to the royal community on Masada (Josephos, Against Apion 1:31-32). In these cases the ancestry of both families was traced for nonfamily blood in the records in Jerusalem. Further support for the importance of these family ties can be seen in the levirate marriage recommendations in the Mishnah (Yevamoth 2:6-8; $3: 1-9$ ), which prescribe that the brother-in-law should marry his brother's widow.

Like the previous religious subsystem, this subsystem focused on the woman. The woman had to be a virgin at marriage and remain sexually linked solely to her husband. Suspicion of extramarital relations or nonvirginal bridehood was just as damning as the actual fact (Mishnah, Dethuboth 1:1-3, 6, 9).

The attached dishonor was quite damaging. Having rights to visit her parents, the wife identified with two families, her husband's and her father's. Any suspicion of sexual misconduct attached to a woman brought 
shame not just to one, but to two houses. The need for this seclusion was also reinforced by the attached value that the woman was more sexually susceptible than the man (Mishnah, Dethuboth 1:6-8). The man had reason (a nonfemale quality) to keep his passions in check.

Based upon this information, our general system paradigm would be

STRUCTURE SUBSYSTEMS

\begin{tabular}{|ll|l}
\hline $\begin{array}{l}\text { Rules restricting } \\
\text { male-female }\end{array}$ & $\begin{array}{l}\text { 1. Family power } \\
\text { relations }\end{array}$ & $\begin{array}{l}\text { 2. Religious } \\
\text { 3. Unknown spatial } \\
\text { symbolic }\end{array}$
\end{tabular}

The structure and subsystems variables are bracketed to show that they are within a "closed system." It is realized of course that such a "closed system" is impossible. There are other variables, beside the obvious functional, that must be correlated to this system as well. But this should not weaken the paradigm, for its identified variables and their intercorrelations are of enough significance to measurably affect $(\rightarrow)$ the material culture pattern.

The specific paradigm. To change our general paradigm into one more specific to the Masadan community we can compare it to examples of similar communities where the ideational background is much better documented and the correlations to the material culture identified. The benefit of having a general paradigm is that in looking to specify it through analogy, it is possible to begin by looking for cultures not only with a similar material pattern but with a similar general paradigm as well. Relational analogy is therefore possible.

A search for good comparative material argues that the opportunity for contemporary relational analogy is unfortunately poor. Investigation shows that our current knowledge of the ideational background to domestic architecture in the then pervasive Greek culture is too limited to make it a good candidate. There are several examples of Greek courtyard houses from Olynthos to Delos, but archaeologists have yet to gain sufficient knowledge of the house to confidently identify spatial-cultural corrclations. Identification of male and female space, the andron and gynaikon, has been on ongoing problem. Although a recent attempt has been made to identify male and female areas in the classical Greek house (Walker 1983) the limits of the documentation and the reliance on formal analogy provide an unsatisfying conclusion, which reinforces Robinson's (1938) initial pessimism over the sexual identification of Greek domestic space.

The greater body of material makes relational analogy to more modern 
societies much more possible. Ethnographic work argues that many communities in the Islamic Middle East share local customs that are very close to the rules regarding male-female relations, suggested for Masada (Antoun 1968; Canaan 1931; Bates and Rassam 1983). In addition, correlated social subsystems in Islamic communities closely match the family power maintenance and religious subsystems, documented for the Masada community. For example, religiously the woman is unclean during menstruation and the time after childbirth. Like Jewish tradition there is also a wide preference for endogamy in the upper classes, which seek to maintain and solidify their political power and preserve group property holdings.

The larger Islamic community would then be a good area in which to search for a similar community spatial pattern. While there has been a good deal of ethnographic work with middle eastern Islamic communities, ethnoarchaeological studies are yet few. Two touch upon architecture, one is an examination of status differentiation in Iranian villages (Watson 1978), and the other is an analysis of the spatial syntax of social relations in the Wa-ungwana Islamic community off the Somali coast (Donley 1982).

It is the Somali study that is of concern. In a study that draws upon ethnohistorical as well as ethnoarchaeological material, Donley outlines a model in which community spaces are corrclated to different community relations. Focusing on the house (Fig. 5) the most private space was the ndani, the innermost room, often on the upper floor. This was family
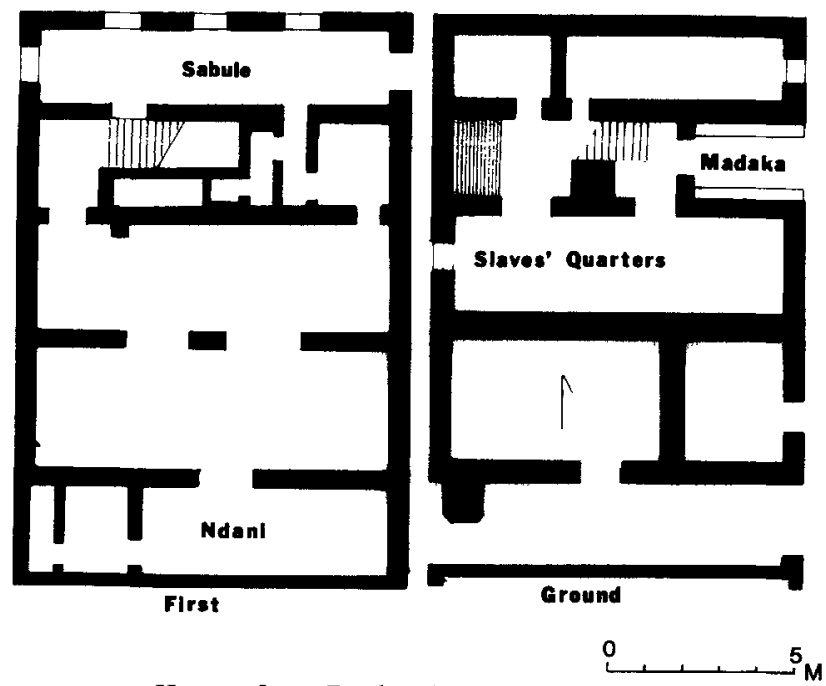

Fig. 5. Wa-ungwanan House, from Donley (1982): Fig. 3; left side, upper story, right side, ground floor. 
space and significantly the secluded domain of the women. Large unadorned rooms on the ground floor were used for the lodging of female domestic slaves (male slaves were not housed in the village), who slept within the house, but were on the perimeter of the family circle. The madaka, a vestibule with benches outside the house door, was the space used for formal family-visitor relations. Aside from the males of the household, only female slaves came in contact with the visitors (exclusively male) at the madaka, when they served refreshments. (It is assumed that informal contact would have been conducted in the larger area of the town, between the house walls and the town wall.) If the visitor was of long-standing relationship and identified as a guest, he would be invited into the sabule, or entertaining room. Some guests lodged there as well, but their communication with the rest of the house was severely restricted.

The ndani secluded women, with their impurity, from social contact. In addition to this spatial manipulation the Wa-ungwana were using a further symbolic system to control impurity in the home. Protective charms and Koranic inscriptions were placed around the house. Within the ndani small niches, resembling mihrabs, decorated the main wall to combat the impurity of the women, who were its most frequent residents.

If we were to establish an ideational paradigm for male-female relations behind the architectural record of this village, the structure would consist of the following suggested rules for family-outsider contact. The rules would be (1) Contact between free women of the house and visitors was prohibited; only female slaves were allowed contact, in the entrance at the madaka. (2) Contact between free women of the house and guests was probably prohibited as well; female slaves were allowed to serve guests in the sabule. (3) Contact between male members of the house and visitors was open but restricted to the madaka. (4) Contact between male members of the house and guests was more open. Guests were invited into the sabule as well as the madaka.

The spatial symboling subsystem among the Wa-ungwana was used to reinforce not only intrafamilial relations, reflected in the position of the slaves quarters, but also these rules regarding family-outsider contact. As a recessed entrance, the madaka partially invited the visitor into the space of the house, but the door to the house put up a strong barrier to further incorporation. The sabule, an area within the house, but separated from the more private sections, recognized that the outsider had guest status and was allowed into the household space, but separated from the innermost space of the house, the ndani, where the free-born women of the house were secluded.

A system paradigm for the ideational background to the Wa-ungwanan spatial syntax would be 


\begin{tabular}{|ll|c}
\hline Rules & 1. Family power & Wa-ungwanan \\
listed & 2. Religious & architectural \\
above & 3. Wa-ungwanan spatial symbolic & spatial \\
& 4. Wa-ungwanan charm symbolic & pattern
\end{tabular}

Because the Wa-ungwanan spatial pattern and system paradigm closely parallel that from Masada, the information gained from this ethnographic study can specify the general paradigm to fit Masada. In regard to architectural patterning, the " $L$ " shaped unit best parallels the position of the Wa-ungwanan ndani. It is the innermost space, separated from the rest of the house and therefore the domain of the household women. The courtyard unit would parallel the Wa-ungwana's sabule. It was within the house, but separated from the innermost spaces. It was guest space. The noncourtyard accessable entrance/exits in house XI and the western palace, which linked the " $L$ " shaped units to the outside, would reinforce this identification by allowing females to leave and return to the innermost household space without meeting parties in the courtyard. The relationship between the courtyard unit and the " $L$ " shaped unit would parallel the relationship of the household slaves to the family. While slaves were members of the family, they were peripheral. The position of the entrance unit, a spatial combination lying between the plateau and the courtyard unit, would correlate well with the Wa-ungwana's madaka. The vestibule, often fitted out with benches at Masada as well, could have been used as a waiting room for visitors meeting with family members in the attached room. Like the Somali system, visitors were thus invited into the greater community space of the plateau and, for formal relations, partially into the house.

A unique feature of the Masada syntax however, lies in the characteristics of the "L" shaped unit, i.e., the separation of its southwest and southeast sections by the open two-columned room. This space was shared by both the courtyard unit and the " $L$ " shaped unit and invited those in the courtyard into the innermost spaces of the house, but provided differential access to its southeast and southwest sections. This unique spatial manipulation may be correlated to the spatial location of women and men in the Masadan house. It may have been that the larger southeast room at Masada was female and the smaller southwest room male. The Mishnah prescribes greater domestic responsibilities for the wife than the husband (grinding corn, baking, washing, cooking, suckling, making husband's bed, working wool; Kethuboth 5:5), which may have necessitated greater domestic space. The largest room in the house, the southeast room could have been the primary female workspace. It 
was out of sight of the nonfamily parties in the courtyard unit, but it caught as much light as possible from the open room through its large doors. If the southwest room was a men's room, the resulting sexual separation from this spatial differentiation would have allowed contact between courtyard parties (guests) and males of the house in a part of the innermost section of the house, (the southwest room) while also facilitating restriction of courtyard party contact with household females.

In regard to the symboling subsystem, by analogy to Wa-ungwana community, the Masadan community was using community space to identify and reinforce family structure and seclude women in family-outside relations. In the house the interface between the "L" shaped unit and the courtyard unit initiated and reinforced differentiating male/female family-guest relations. The entrance unit, recessed but separated from the rest of the house, created and reinforced the structure of formal visitor-family contact, as opposed to guest-family or more informal meetings on the plateau.

Additionally, if the space had this meaning and manipulation, the organization of the Masadan houses would have supplied the following rules: (1) Contact between free women of the house and visitors was prohibited. Slave women could come in contact with visitors in the entrance units. (2) Contact between free women of the house and guests was limited to the courtyard area (in houses with no back entrance/exit) and perhaps to the male section of the "L" shaped unit. Female slave-guest contact could be less space-restricted. (3) Contact between male members of the house and visitors was to be held in the larger community space outside the house or in more private space within the house entrance. Female slaves may have come into contact with visitors, while attending in the vestibule. (4) Contact between male members of the house and guests was to be less restricted. Unlike visitor contact, this may take place within the courtyard and the male section of the "L" shaped unit as well.

Our specific paradigm would then be

STRUCTURE

Proposed

rules

above
SUBSYSTEMS

1. Family power

2. Religious

3. Points above
Masadan architectural $\rightarrow$ spatial pattern

\section{Testing Structural Models in Historical Archaeology}

Unlike the treatment of analogy in prehistoric research, support for the analogically built paradigm can be sought in testing some of its hypoth- 
eses on independent data. This is possible because historic documentation allows the determination of ideational backgrounds to material patterning at other sites. ${ }^{2}$

System paradigms may be tested by predicting the outcome of measured variability (Tuggle et al. 1972). If the specific Masadan model is valid, alteration in its structure and subsystems at other contemporaneous Jewish sites where documentation argues that their structural pattern would contrast with that of Masada, should produce predictable alterations in the architectural spatial pattern. So far the knowledge of other contemporaneous sites is still limited. But in obvious examples, such as contemporary Qumran (de Vaux 1956), where textual material (Josephos, Wars 2:121-133) argues that it was a mostly male religious community which would therefore engender a different paradigm, the different spatial syntax argues that alteration is already broadly identifiable.

We are left to conclude that the additional information gained from textual sources in historic archaeology permits the use of relational analogy both to build specific ideational paradigms for the specific material pattern and promises to strengthen these paradigms by testing hypotheses based upon system variation against independent material.

\section{THE STRUCTURALIST APPROACH TO ESTABLISHING IDEATIONAL LINKAGES BETWEEN ETHNOARCHAEOLOGICAL OBSERVATIONS AND PAST CONTEXTS, AND HISTORIC ARCHAEOLOGY'S ROLE IN ITS METHODOLOGY}

It has been argued that in building a structuralist model the archaeologist should make use of "general principles of symbolism" and "generalisations about the links between those principles and the context in which they are used" (Hodder 1982b:26). An understanding of these principles and correlations comes from ethnoarchaeologically observed conditions. The choice of these "general principles" and generalizations of their correlations for an archaeological model is determined by the neatness of their analogic fit into the specific archaeological case (Wylie 1982).

While calling for the recognition of "general principles of symbolism" and "generalisations about the links between those principles and the context in which they are used," structuralist archaeology has yet to develop methods of selecting what general principles and generalizations of correlations would be applicable in archaeological study. A good place to begin would be in historic archaeology. Work in historic contexts can provide present-past structural linkages. The work presented in this paper has identified an ideational principle which is attestable in the past. 
This principle lies in the paradigm of the ideational background to the architectural pattern in the Somali community. That within the paradigm that is attestable on Masada is the presence and correlation of the spatial symboling system, which established and reinforced the relationship between guests and family members, or visitors and family members; rules regarding male-female contact; and connected systems such as the religious and family power maintenance.

Sharper definition of the character of this present-past attested principle may be sought in contrasting the contexts of the two communities to further examine the change or immutability of the different facets of this principle in a cross-cultural context. There is probably less similarity between the two communities than one would imagine. True, the structural similarity between Masada and the enthnographic example is most likely due to cultural continuity, both communities culturally tied to a larger and older Near Eastern cultural group. But the assumption that structure, moving in cultural continuity is largerly unchanged over time and space or that its context remains relatively stable is more suspect than initially thought (Watson 1979; Gould and Watson 1982). In fact, this ideational principle was working in two quite different contexts. Masada was a community within the larger Jewish nation of the late first century B.C. The Wa-ungwana town is peopled by one-time Arabs, who have lost much of their ethnic heritage. In each context the principle correlated with different ideational systems. For example, Masada was a royal estate and the ideology of kingship must have been important in its daily life. On the other hand, the Somali community was peopled by urban traders who were using a symboling system to establish themselves in an economic position superior to the inland tribes.

Because of the contrasts in two communities linked by cultural continuity, the principle identified in this context does have cross-cultural application. Additionally, the example in this paper utilized two cultures which were part of a much larger culture group, future work could focus on cultures with no culture group affiliation.

Historical archaeology thus supplies a means by which structuralist archaeology can identify Hodder's (1982b:26) "general principles of symbolism" and "generalisations about the links between those principles and the context in which they are used." These principles should form a body of knowledge which could be utilized for ideational reconstruction of the past, not only historic, but prehistoric as well.

\section{CONCLUSION}

This paper has attempted to show how historic research can help structuralist archaeology meet the challenges of the concerns over the appli- 
cation of ethnoarchaeology. In historic periods the benefit of texts gives the archaeologist the opportunity to build paradigms through the use of analogy that is questioned in prehistoric research. This type of ideational identification isolates principles that, because of their chronological dimension can serve as linkages to past societies. If we are going to begin to develop a competent structuralist archaeology, we must set ourselves to the task of using historical archaeology to its greatest extent.

\section{ACKNOWLEDGMENTS}

I was aided considerably in forming the ideas for this paper and in correcting drafts by Drs. Brian Hesse, Paula Wapnish, University of Alabama at Birmingham; Antony Snodgrass, Cambridge University; and Tom Gallant, University of Florida at Gainesville.

\section{NOTES}

'The isolation of this community on Masada is based upon personal research, conducted in the winter of 1981-1982, with several follow-up sessions, while an NEH and Dorot Fellow at the Albright Institute in Jerusalem during 1984. This conclusion, as well as an account of the architectural phasing, is being prepared for independent publication. Specifically, the buildings in the community are isolated from other architecture on the plateau by differences in materials, artistic treatment of entrances, architectural phasing, and documentary accounts.

${ }^{2}$ Hypotheses applied to the patterning of other possible similar relation-specific (textually identified) material on the same site would be valid as well. In Masada's case this is not possible, because of the great amount of post-Hellenistic transformation and the less than adequate excavation methods.

\section{REFERENCES CITED}

Antoun, R. T.

1968 On the modesty of women in Arab muslim villages: a study in the accommodation of traditions. American Anthropologist 70:571-597.

Avi-Yonah, M., N. Avigad, Y. Aharoni, I. Dunayevsky, and S. Gutman

1956 The archaeological survey of Masada, 1955-56. Israel Exploration Journal $7: 1-60$.

Bates, D. G., and A. Rassam

1983 Peoples and cultures of the Middle East. Prentice-Hall, Englewood Cliffs.

Binford, $L$.

1978 Nunamiut ethnoarchaeology. Academic Press, New York

Canaan, $\mathrm{T}$.

1931 Unwritten laws affecting the Arab woman of Palestine. Journal of the Palestine Oriental Society 11:172-203.

de Vaux R.

1956 Fouilles de Khirbet Qumran. Rapport preliminaire sur les $3 \mathrm{e}$, 4e, et $5 \mathrm{e}$ campagnes. Revue Biblique 63:533-577.

Donley, L. W.

1982 House power: Swahili space and symbolic markers. In Symbolic and structural 
archaeology, edited by I. Hodder, pp. 63-72. Cambridge Univ. Press, CamFritz, J. M. bridge.

1978 Paleopsychology today: ideational systems and human adaptation in prehistory. In Social archaeology: beyond subsistence and dating, edited by C. L. Redman, M. J. Berman, E. V. Curtin, W. T. Langhorne, Jr., N. M. Versaggi, and J. C. Wanser, pp. 37-60. Academic Press, New York.

Gould, R.

1980 Living archaeology. Cambridge Univ. Press, Cambridge.

Gould, R., and P. J. Watson

1982 A dialogue on the meaning and use of analogy in ethnoarchaeological reasoning. Journal of Anthropological Archaeology 1:355-381.

Hodder, I.

1982a Theoretical archaeology: a reactionary view. In Symbolic and structural archaeology, edited by I. Hodder, pp. 1-16. Cambridge Univ. Press, Cambridge.

1982b The present past: an introduction to anthropology for archaeologists. Pica Press, New York.

Leach, E.

1973 Concluding address. In Explanation of culture change, edited by C. Renfrew, McIntosh, $\mathbf{R}$. pp. 761-771. Duckworth, London.

1985 Review of The present past: an introduction to anthropology for archaeologists by I. Hodder. Archaeology 38:68.

Robinson, D. M.

1938 Excavations at Olynthos VIII: the Hellenic house, pp. 167-169. Johns Hopkins, Baltimore.

Schiffer, M. B.

1976 Behavioral archaeology. Academic Press, New York.

Tuggle, David H., Alex H. Townsend, and Thomas J. Riley

1972 Laws, systems, and research designs: a discussion of explanation in archaeology. American Antiquity 37:3-11.

Walker, S.

1983 Women and housing in classical Greece: the archaeological evidence. In Images of women in antiquity, edited by A. Cameron and A. Kuhrt, pp. 81-91. Croom Helm, London.

Watson, P. J.

1978 Architectural differentiation in some Near Eastern communities, prehistoric and contemporary. In Social archeology: beyond subsistence and dating, edited by C. L. Redman, M. J. Berman, E. V. Curtin, W. T. Langhorne, Jr., N. M. Versaggi, and J. C. Wanser, pp. 131-58. Academic Press, New York.

1979 The idea of ethnoarchaeology: notes and comments. In Ethnoarchaeologyimplications of ethnography for archaeology, edited by C. Kramer, pp. 277-287. Columbia Univ. Press, New York.

Wylie, M. A.

1982 Epistemological issues raised by a structuralist archaeology. In Symbolic and structural archaeology, edited by I. Hodder, pp. 39-45. Cambridge Univ.

Yadin, Y. Press, Cambridge.

1965 The excavations of Masada, 1963-64, preliminary report. Israel Exploration Journal 15:1-60. 